\title{
Kids' Furniture Market according to Ergonomical and Environmental Design
}

\begin{abstract}
Dr. Sadia Farooq

The rapid progress in the furniture industry has changed the needs and demands of the consumers. In this era a small product is very important in its design, material, strength and usage. The same case is in the kids' furniture, kids are our future so they need the items which are most appropriate to their body and comfort needs. Kids from age five and above get into the age where they require proper atmosphere for their best growth patterns. Ergonomics is the science which design according to the posture, to avoid future hazards such as back ache, pains and body deformation. A few numbers of designers were combining local and international standards and almost $50 \%$ designers were taking anthropometric measurements. More than $70 \%$ designers were taking up to $20 \%$ profit on kids' furniture. Designers take almost 40 days for the completion of the furniture items. Wood used extensively by the designers for kids' furniture because of its durability and ease of maintenance, along with that plastic, fiber glass, foam and fabric were also in use. Most of the designers gave guarantee up to six years which is appropriate to satisfy a customer. Most of the designers were choosing colors from magazines and form internet, with the choice of parents. Varnish and lacquer were mostly used finishes for kids' products. Nontoxic colors were being selected by most of the designers. The term ergonomics was known by $70 \%$ interior designers and $50 \%$ manufacturer but carpenters were not having much idea about the term and its usage in kids' furniture. The study investigates that the ergonomically designed and environmentally safe products are being manufactured in the local market for kids but not to the larger extend.
\end{abstract}

Keywords: Kids' Furniture, Ergonomics, Environment, Market

\section{INTRODUCTION}

Man has progressed through the ages because of his ability to pass the experiences along from one generation to another. This progressive journey has seen many eras from using tree trunks to sit in to the new age of manufacturing comfortable and luxurious seating ornaments by man. This is possible because of industrial revolution in the world, by this change the furniture industry also flourished and now furniture became the necessity of life. The research revolves around the use of functionalism (ergonomics) in furniture designed for kids. Now people are more concerned about designed furniture for comfort and safety of their child than previous years (Dudek, 1996).

As considering kids from age five, products and their designs get importance in their rooms. Kids from age five and above get into the age where they require proper atmosphere for

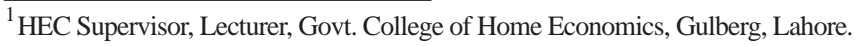

\begin{tabular}{llll|l}
\hline JISR-MSSE & Volume 14 & Number 1 & Jan-June 2016 & 79
\end{tabular}


their best growth patterns. Designing for kids, as individual is a wonderful and rewarding challenge, but it is not as simple as it may appear.

The designer must think about a kids' product with a different attitude than he would design for others. Take a look at group of five to six years old as they play and you will notice that for the most part they move with ease and agility, then watch some seven to eight years olds and notice the beginnings of hunched shoulders, tight necks and restricted breathing that can also be seen more fully developed in many adults. "The designers must consider safety, size, colour, toxicity, motor control and the product's overall quality. In other words a product must be designed ergonomically". (Chesler,1988) If ergonomics is described, it "is a word made up of Greek words, ergo means work and norms mean law..." (Britannica, 2015) Ergonomics is also "an applied science concerned with designing and arranging things people use, so that the people and things interact most efficiently called also human factor engineering. (Britannica, 2015)

Functional and non-toxic products must be designed for children to protect them from inner injuries especially in their future life and from toxic effects, to provide our younger generation health, safety and relaxation (Ruth, 2000).

Children are our future and we do most of the deeds for them, so it is also our duty to protect them from the upcoming dangers in their lives. Ergonomically designed furniture is very important for a child to protect him from inner injuries in later age which is clear in the below given saying. "Death is not the greatest lost in life, the greatest lost is what dies inside us when we are alive."(Norman Cousin, 1985)

In our country the furniture market is too narrow to design for a child, but some designers are practicing to design for children, a survey included to this study would describe, how much children's products are being designed according to standards set for different ages and their usefulness in our society. Many designers and carpenters do not consider the bad effects and toxicity of the materials used for children e.g. effects of different materials, finishes and fibers. The materials being used are wood, metals, cane, plastics, fiberglass and each of that has its own properties. Out of these some would be environment friendly when used or many leave some bad effects on child skin. Some fibers are natural others synthetic and the soft materials used for upholstery in children's furniture result best.

The younger children adopt postures in which reflex control is dominant. They sit in many ways, but each with the head, spine and neck relationship retained. Later on they may sit in slumped postures, which owe little to older reflex control (Bukhari \& Most, 1993). Children in sitting position have their vitality seem to go. Their headrest heavily on their shoulders, the ribs press into their lungs, slumped posture normal. It does not seem any sign that children made the transitions consciously, or that they feel better as a result. "Whilst low esteem and peer pressures are factors in poor posture, the most significant factor appears to be badly designed furniture". (Chesler, 1988)

There is no universal furniture product to follow. The idea of a product is only present in examples. One of the first principles in ergonomics is that there is no such thing as an ergonomic product without the user and context. Referring to an ergonomic product is meaningless. No product works for every user and situation. Of course some products clearly

\begin{tabular}{l|llll}
\hline 80 & Jan-June 2016 & Volume 14 & Number 1 & JISR-MSSE
\end{tabular}


accommodate a large proportion of people than others do. Ergonomics have largely replaced comfort with discomfort. Products need to be considered on individual bases. The design of a product should be easy to use by its intended audience. In the case of children's product they should be scaled to small hands, fingers feet, and toes and so on. In the United States the department of commerce's Bureau of standards is responsible for establishing product standards" (Humanics-es.com) also used as objectives of the study.

The factors which are important in children's furniture are given below:

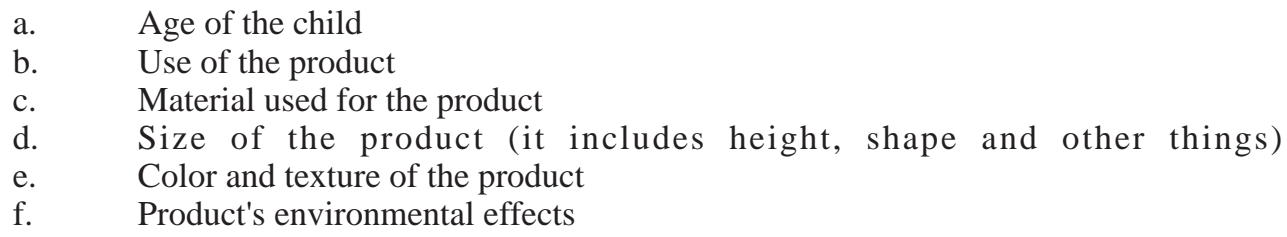

\section{Objectives}

The study investigated the designer's contribution towards the awareness and manufacturing of children furniture according to ergonomic standards.

- To find out the current position of the kids' furniture market.

- To enlist the deficiencies in kids' furniture market

- To know the awareness level of the designers about egronomical and environmental kids' furniture products.

- To know about the rules of ergonomics and environment being followed in kids' furniture market

- To analyze about future projections for kids' furniture market.

\section{METHODOLOGY}

Thirty five showrooms of furniture were selected purposefully from the furniture market who designs furniture for kids. A questionnaire was prepared to know about kids' products in the market. There were different questions asked to the designers to evaluate their knowledge about making a product ergonomically and environmentally by following different standards. The questions were having different options according to the type of the question, which chosen after a survey of the market. The term designer was used collectively for all the persons who design and make furniture for kids whether interior designers, manufacturers

Figure. 1

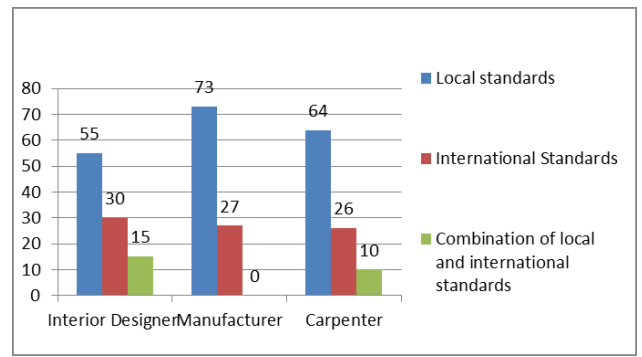


or carpenters.

\section{DATA ANALYSIS}

The data was analyzed on the percentages. Following are the assessment features: Standards being followed by the designers:

This question was asked to the designers about the standards being used, the options were

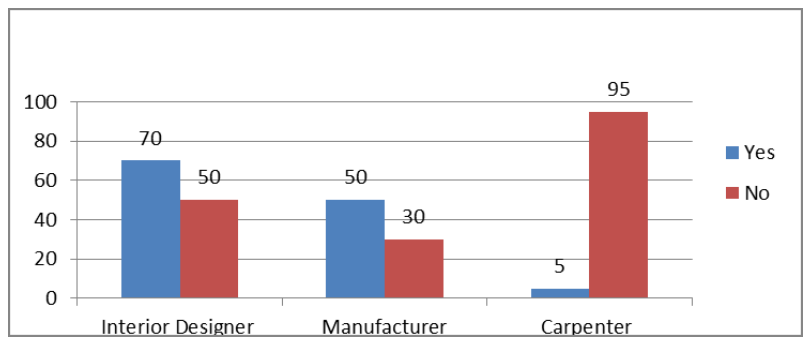

Figure 2 Awareness about Ergonomics

Figure 2 shows that when a question asked about the awareness of term ergonomics, $70 \%$ interior designers and 50\% manufacturers were aware of it. Only $5 \%$ carpenters were having information about the term ergonomics.

\section{Awareness and use of the designers about Anthropometric measurements}

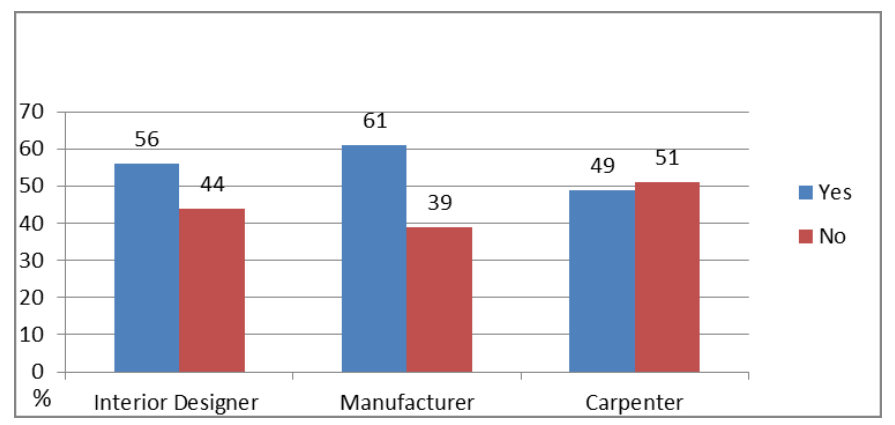

Figure 3 Awareness and use of Anthropometric Measurements of the Kids

Figure 3 shows that designers were conscious to take body measurements of the kids such as 56\% interior designers, $61 \%$ manufacturers and $49 \%$ carpenters were taking anthropometric measurements. This concludes that almost half of the designers were taking anthropometric measurements so awareness must be increased about taking anthropometric measurements of the user of the product.

\section{Colors for kids' furniture}

The question was related to the color scheme of a product, because colors for kids products must also be interesting for kids as well as for market growth.

\begin{tabular}{l|llll}
\hline 82 & Jan-June 2016 & Volume 14 & Number 1
\end{tabular} 
Figure. 4

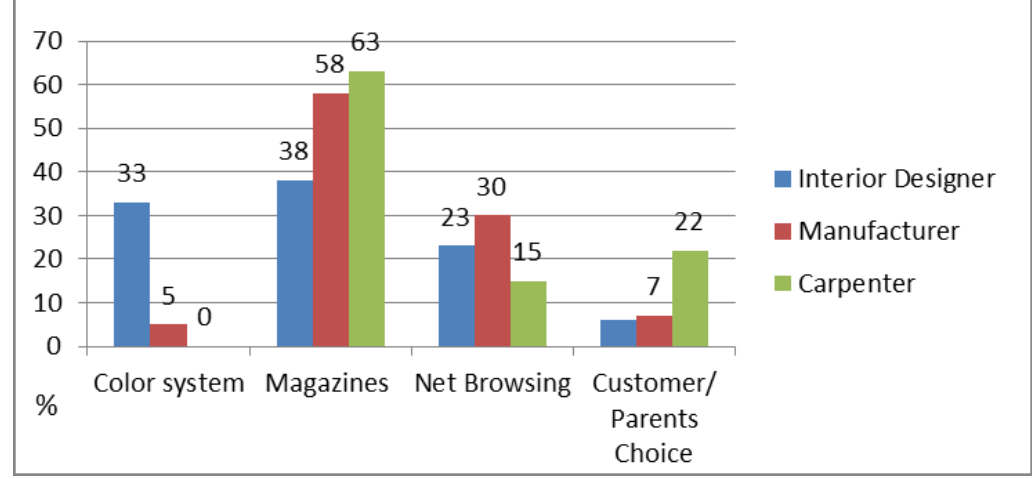

Figure 4 shows that most of the designers were choosing colors form the magazines and after that they were choosing from internet. But along that they also consider parents' choices. Color systems were preferred by interior designers such as $33 \%$ of them were using color systems. This concludes that the designers were aware of latest and new trends and colors about kids' furniture which can raise the competition among designers in the market about kids' furniture and interior designers were also using their knowledge of color systems in this field.

\section{Selection of environment friendly colors for kids' furniture}

Figure. 5

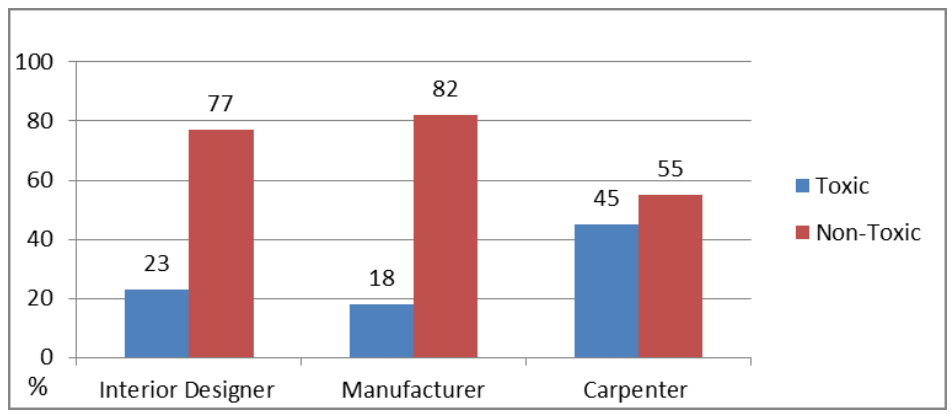

Figure 5 shows that most of the interior designers, manufacturers and carpenters use nontoxic colors such as $77 \%$ interior designers, $82 \%$ manufacturers and $55 \%$ carpenters were using nontoxic colors. This concludes that mostly environmentally healthy colors were being used for kids' furniture in the market. 


\section{Selection of finishes for kids' furniture}

Figure. 6

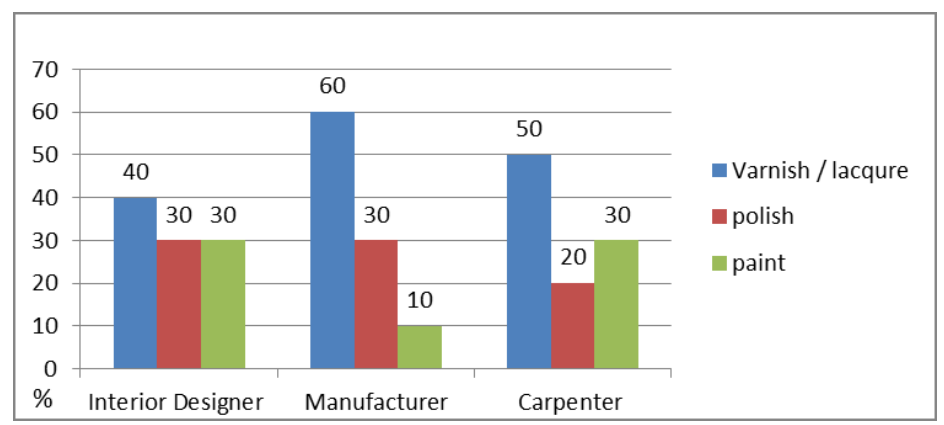

Figure 6 shows that varnish and lacquer both were being used by most of the interior designers, manufacturers and carpenters. Then the second choice was polish and paint, both were used in different ratios. This concludes that the finishes which give shine to the product were more in use than dull finishes.

\section{Materials used for kids' furniture}

The question was related to the materials available and being used in kids' furniture and to conclude about the suitable material for kids.

\section{Figure. 7}

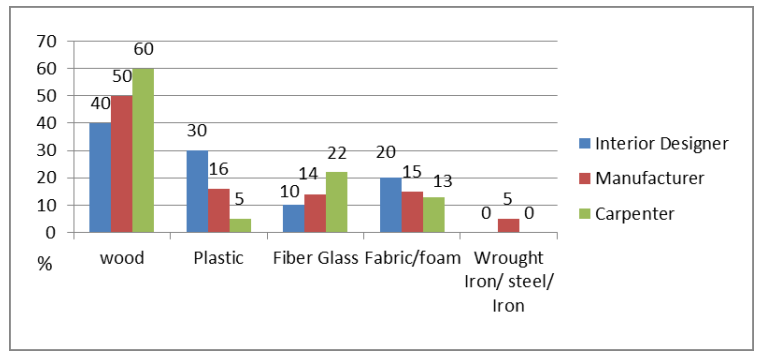

\section{Figure 7 Materials used for Kids' furniture}

Figure 7 shows that wood is the material which is used extensively by all the designers but other material such as plastic, fiber glass, fabric and foam were also in use. The material which is not extensively used is wrought iron, steel and iron, these material are hard and can injure kids while playing. This concludes that the sustainable and nonhazardous materials were being selected for kids' furniture. 


\section{Days required for completion of the product}

The question was to conclude about the days, the designers require for the completion of a kid's product.

Figure. 8

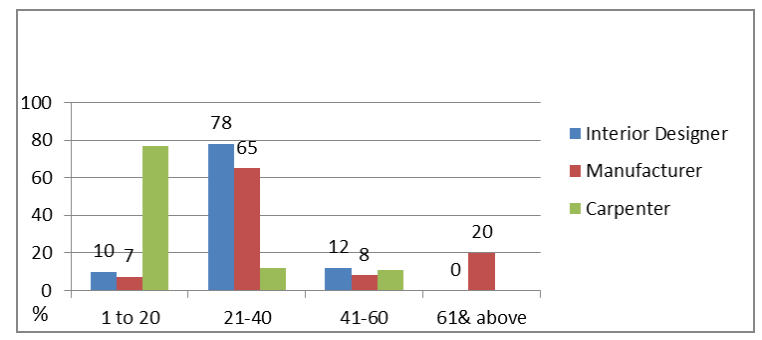

Figure 8 shows that designers took almost 40 days for the completion of the products which is an appropriate time for the customers to wait for a new furniture item. This time limit also favorable in expanding the furniture products for kids in the market because when a product would take longer for completion it may slow down the market growth plus customer interest in that product.

\section{Profit intake}

When profit is more than a limit it creates hurdles in establishing the business of a certain product. The question was related to the profit intake from the customers on kids' furniture.

Figure. 9

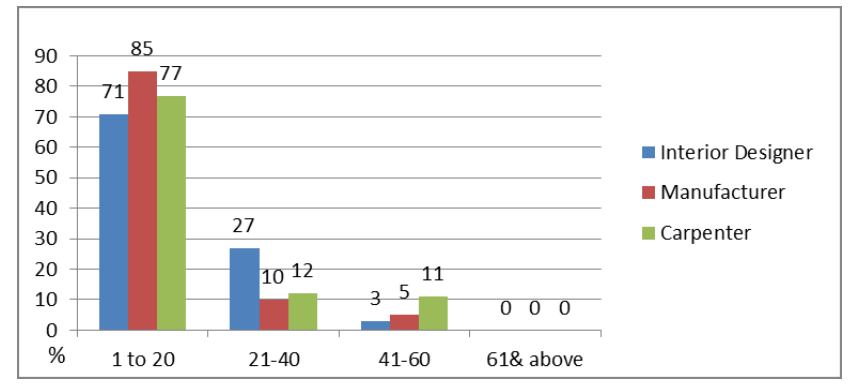

\section{Figure 9 Profit Percentage on Kids' furniture}

Figure 9 shows that more than $70 \%$ of the interior designers, manufacturers and carpenters were taking 1 to $20 \%$ profit on kids' furniture. A small percentage of the designers were taking profit between $20 \%$ to $60 \%$ but not more than this limit.

This concludes that a reasonable percentage of profit is favorable to increase the market of kids' furniture. 


\section{Guarantee Period on the kids' furniture}

The question related to the guarantee of a product was added because guarantee period also favors the designers, while choosing them for buying a product.

Figure. 10

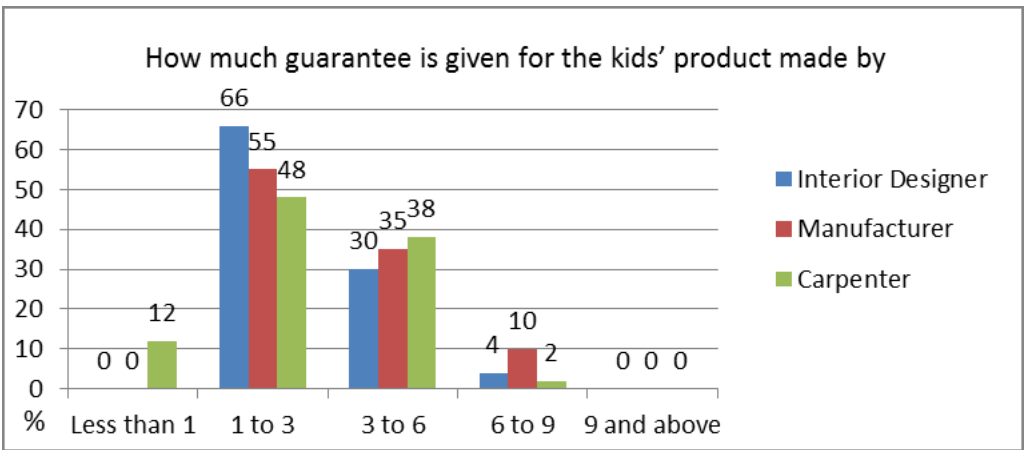

Figure 10 shows that most of the designers were giving guarantee of one to six years which is appropriate to satisfy a customer about a furniture product.

This also concludes that the designers are making durable products which can last longer, this attitude satisfy customers and build confidence on the designers. This attitude can also increase in kids; furniture market.

\section{FINDINGS}

A few numbers of designers were combining local and international standards and almost $50 \%$ designers were taking anthropometric measurements.

- More than $70 \%$ designers were taking up to $20 \%$ profit on kids' furniture.

Designers take almost 40 days for the completion of the furniture items.

- Wood was used extensively by the designers for kids' furniture, along with that plastic, fiber glass, foam and fabric were also in use.

- Most of the designers gave guarantee up to six years which is appropriate to satisfy a customer. Most of the designers were choosing colors from magazines and form internet, with the choice of parents.

- Varnish and lacquer were mostly used finishes for kids' products.

- Nontoxic colors were being selected by most of the designers.

The term ergonomics was known by $70 \%$ interior designers and $50 \%$ manufacturer but carpenters were not having much idea about the term and its usage in kids' furniture.

\begin{tabular}{l|llll}
\hline 86 & Jan-June 2016 & Volume 14 & Number 1 & JISR-MSSE
\end{tabular}




\section{CONCLUSION}

The conclusion of the study is that the environmentally safe and ergonomically designed products are being manufactured in the local market but not on a large scale, the designers are trying their best to increase their market sale and to provide a best product according to the provided standards and plus for customer's satisfaction. Designers were aware of new color trends and changes which occur internationally. Awareness must be increased about taking anthropometric measurements to get a right product according to users' body needs. A reasonable amount of profit was being taken which is favorable both for designers and customers. The days required for completion of the product is reasonable and favorable in expanding the furniture industry for kids.

That would be in front of our eyes to see a vast furniture industry especially for children in a few years. So this concludes that kids market will be flourished in upcoming years but a few things need consideration such as anthropometric measurements and to combine local and international standards to meet the requirements of the kids' body.

\section{RECOMMENDATIONS}

The international standards must emerge with local standards according to our kids' needs, so an experimental study may be conducted with the use of standards after merging the local, individual and international standards. There must be a national or provisional organization that would set standards according to local needs and requirements of the children.

\section{REFERENCES}

Anita Rui Olds (1987), Bachelor of Architecture, Department of Architecture, Kulliyyah of Architecture and Environmental Design, International Islamic University Malaysia

Bandini (1994), "Typological Theories inarchitectural design?, Child Care DesignGuid, New York,Ny; Mc Graw-Hill

Companion toContemporary Architectural Thought, Routledge, London

Encyclopedia Britannica retrieved from https://www.britannica.com

Hadith Bukhari and Muslim Most.P (1993), "Environment", Quality in https://www.brainyquote.com/quotes/authors/n/norman_cousins.html

Joseph Featherstone articles published in Linda Cain Ruth (2000), Design standards for children environment, Mark Dudek (1996), Kindergarten Architecture, United Kingdom,UK; E\&FNSpoon, an imprint of Chapman \& Hall. 
Merriam-Webster dictionary (2010),retrieved from http://www.merriam-webster.com/cgibin/book.pl?five-lang.htm\&1UNESCO Institute for Statistics, Data Centre,http://stats.uis.unesco.org/unesco/ReportFolders/ReportFolders.aspx

Norman Cousins Quotes - BrainyQuote

Phyllis Chesler, 1988. With Child Amazon books

Prof David C. Caple (2008), NES Conference, Ergonomics is a lifestyle (PDFdocument)

Services for Young children- A discussion Paper, European commission Child Care Network, Thomas Coram Research Unit,27-28 Woburn Square, London, p.11

The 1960s in The New Republic Statistic by Department of statistic and economic planning unit, retrieved from: www.malaxi.com

World Health Organization (WHO), retrievedfrom www. who. Int

Www. Humanics-es.com 